\title{
INFLUENCE OF THE ANTARCTIC OZONE HOLE OVER SOUTH OF BRAZIL IN 2010 AND 2011
}

http://dx.doi.org/10.4322/apa.2014.058

\section{Damaris Kirsch Pinheiro ${ }^{1, *}$, Lucas Vaz Peres ${ }^{1}$, Natália Machado Crespo ${ }^{1}$, Nelson Jorge Schuch², Neusa Maria Paes Leme ${ }^{3}$}

\author{
${ }^{1}$ Laboratório de Ciências Espaciais de Santa Maria, Universidade Federal de Santa Maria - UFSM, Av. Roraima, 1000 \\ Camobi, CEP 97105-900, Santa Maria, RS, Brazil \\ ${ }^{2}$ Centro Regional Sul de Pesquisas Espaciais, Instituto Nacional de Pesquisas Espaciais, Campus Universitário, \\ CP 5021, CEP 97105-970, Santa Maria, Brazi \\ ${ }^{3}$ Centro Regional do Nordeste, Instituto Nacional de Pesquisas Espaciais, Rua Carlos Serrano, 2073, \\ Lagoa Nova, CEP 59076-740, Natal, RN, Brazil \\ *e-mail: damaris@ufsm.br
}

\begin{abstract}
The Antarctic Ozone Hole is a cyclical phenomenon, which occurs over the Antarctic region from August to December each year. The polar vortex turns it into a restricted characteristic dynamics for this region. However, from time to time, some air masses with low ozone concentration could escape and reach regions of lower latitudes. The aim of this study is analyzed the influence of the Antarctic Ozone Hole over the South of Brazil in the years 2010 and 2011. To verify these events, ozone total column from OMI Spectrometer overpass data for the coordinates of Southern Space Observatory $\left(29.42^{\circ} S\right.$ and $\left.53.87^{\circ} W\right)$, in São Martinho da Serra, South of Brazil was used. In addition to OMI data, potential vorticity maps using GrADS (Grid Analysis and Display System) generated with the NCEP reanalysis data and air mass backward trajectories, using the HYSPLIT model of NOAA, were analyzed. Ozone total column for the days with low ozone were compared with monthly climatological average from 1981 to 2011. Considering only the days with ozone lower than climatological means minus 1.5 standard deviation, increased absolute potential vorticity and backward trajectories indicating the origin of polar air masses, 4 events in 2010 and 3 events in 2011 , with an average decreased about $6.3 \pm 2.1 \%$ when compared with climatological means, were observed in the period analyzed.
\end{abstract}

Keywords: mid-latitude, potential vorticity, backward trajectories, Antarctic ozone hole

\section{Introduction}

Potential Vorticity (PV) has an important hole at air mass dynamic movement, having a behavior like a material surface where potential temperature is preserved (Hoskins et al., 1985), being used in studies correlating PV and trace gases like ozone and water vapour over isentropic surfaces in low stratosphere (Danielsen, 1968). The domain of the Antarctic polar vortex and its filaments was define as being the region with high PV gradient, where air masses with lower PV than the boundary of the outside region were included inside the vortex, conserving differences chemical characteristics, and the center of the vortex with the minimum PV region or maximum Absolute PV (APV) (Marchand et al., 2005). The PV variation over isentropic surfaces can be used to transport ozone in stratosphere (Jing et al., 2005). An increase at the APV indicated a polar origin of the poor ozone air mass (Narayana Rao et al., 2003; Semane et al., 2006). The polar origin of an air mass can be show also with backward trajectories (Gupta et al., 2007). Although the stability of the polar vortex, air masses could come out of its filaments and reach mid and low latitudes, causing a temporary decrease in ozone concentration. Prather \& Jaffe (1990) calculated that Antarctic air masses could be isolated for 7 to 20 days after their separation of the vortex, time sufficient to propagate toward mid and low latitudes. This phenomenon was first observed over South of Brazil by Kirchhoff et al. (1996). 


\section{Materials and Methods}

Events of Antarctic ozone hole influence over South of Brazil in 2010 and 2011 were detected using overpass data of ozone total column from Ozone Monitoring Instrument (OMI) inside ERS-2 satellite for Southern Space Observatory SSO/CRS/INPE - MCTI (29.4 ${ }^{\circ} \mathrm{S}$ and $\left.53.8^{\circ} \mathrm{W} ; 488.7 \mathrm{~m}\right)$, in South of Brazil. OMI ozone total column was compared with monthly climatological averages from 1981 to 2011 obtained by Brewer Spectrophotometer, installed at SSO, Total Ozone Mapping Spectrometer (TOMS), inboard Nimbus-7, Meteor-3 and Earth Probe, National Aeronautics and Space Agency (NASA) satellites, and OMI from 2006. For the days with ozone total column lower than climatological average minus 1.5 standard deviation, isentropic analysis using Potential Vorticity maps were made with National Centers for Environmental Prediction/Atmospheric Research (NCEP/NCAR) reanalysis data (http://www.cdc. noaa.gov/cdc/reanalysis/reanalysis.shtml). These PV maps were generated with GrADS (Grid Analysis and Display System). The analysis verifies if there was an increase at Absolute Potential Vorticity, indicated the polar origin of the ozone poor air mass. The confirmation of the polar origin can be obtained by air masses backward trajectories using HYSPLIT (HYbrid Single-Particle Lagrangian Integrated Trajectory) model, developed by National Oceanic and Atmospheric Agency (NOAA) and Australia's Bureau of Meteorology (http://www.arl.noaa.gov/ready/open/traj. html).

\section{Results}

Monthly Climatological averages of ozone total column measured by Brewer Spectrophotometer, TOMS and OMI for Southern Space Observatory from 1981 to 2011 were $291.9 \pm 12.5$ DU for August, 298.3 \pm 9.8 DU for September and $292.8 \pm 10.1$ DU for October. The days of 2010 and 2011 with ozone total column lower than these climatological averages minus 1.5 times the standard deviation was analyzed according to the methodology described above.

The examples of October, $22^{\text {th }} 2010$ and October, $21^{\text {th }} 2011$ are shown in Figure 1 and Figure 2, respectively, where an increase of absolute potential vorticity at the level of $620 \mathrm{~K}$ (a), the backward trajectories of air masses poor of ozone (b) and OMI data (c) are represented showing the influence of Antarctic Ozone Hole over South of Brazil. Considering only the days with decreased ozone measured at Southern Space Observatory, increased absolute potential vorticity shown at GRADS maps and HYSPLIT backward trajectories indicating the origin of polar air masses, it was observed 4 events in 2010 and 3 events in 2011 presented at Table 1, with an average decreased about $6.3 \pm 2.1 \%$ when compared with climatological means.

\section{Discussion}

Similar events of low ozone air masses intrusions from Antarctic ozone hole toward mid latitude like those analyzed here were also observed over South America (Kirchhoff et al., 1996; Perez et al., 2000), Southern Africa (Semane et al., 2006)

Table 1. Events of the Antarctic ozone hole influence over Southern Space Observatory showing the date, ozone total column, its corresponding monthly climatological average and the respectively reduction of ozone.

\begin{tabular}{cccc} 
Event Date & $\mathbf{O}_{3}$ Total Column (DU) & $\begin{array}{c}\mathbf{O}_{3} \text { Monthly Climatological } \\
\text { Average (DU) }\end{array}$ & $\begin{array}{c}\mathbf{O}_{3} \text { Total Column Reduction } \\
(\%)\end{array}$ \\
\hline 08/08/2010 & 271,2 & $291,9 \pm 12,5$ & 7,1 \\
09/08/2010 & 280,8 & $298,3 \pm 9,8$ & 5,9 \\
$10 / 13 / 2010$ & 276,2 & $292,8 \pm 10,1$ & 5,7 \\
$10 / 22 / 2010$ & 261,8 & $292,8 \pm 10,1$ & 10,6 \\
09/05/2011 & 283,7 & $298,3 \pm 9,8$ & 4,9 \\
09/29/2011 & 283,3 & $298,3 \pm 9,8$ & 5,0 \\
10/21/2011 & 278,7 & $292,8 \pm 10,1$ & 4,8 \\
Average & $276,5 \pm 7,8$ & & $6,3 \pm 2,1$ \\
\hline
\end{tabular}

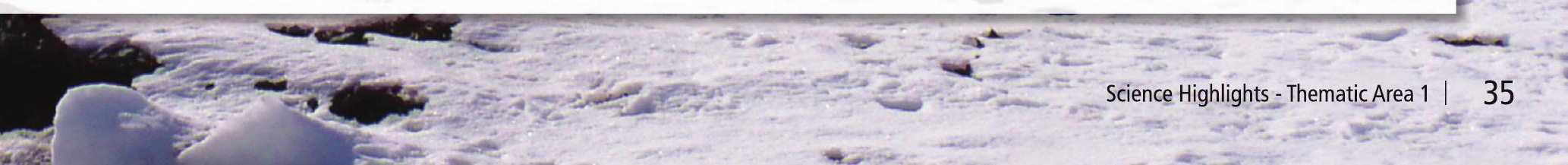


and New Zealand (Brinksma et al., 1998). Comparing the events analyzed with the events observed for Pinheiro et al. (2011) over South of Brazil in 2008 and 2009, the events for 2010 and 2011 had a less intense decrease of $6.3 \pm 2.1 \%$ compared to $9,7 \pm 3,3 \%$ from 2008 and 2009 .

\section{Conclusion}

Days with decrease of ozone total column at Southern Space Observatory for 2010 and 2011 were analyzed. A total of seven events of influence of the Antarctic Ozone Hole over South of Brazil were detected in these period, with 4 events

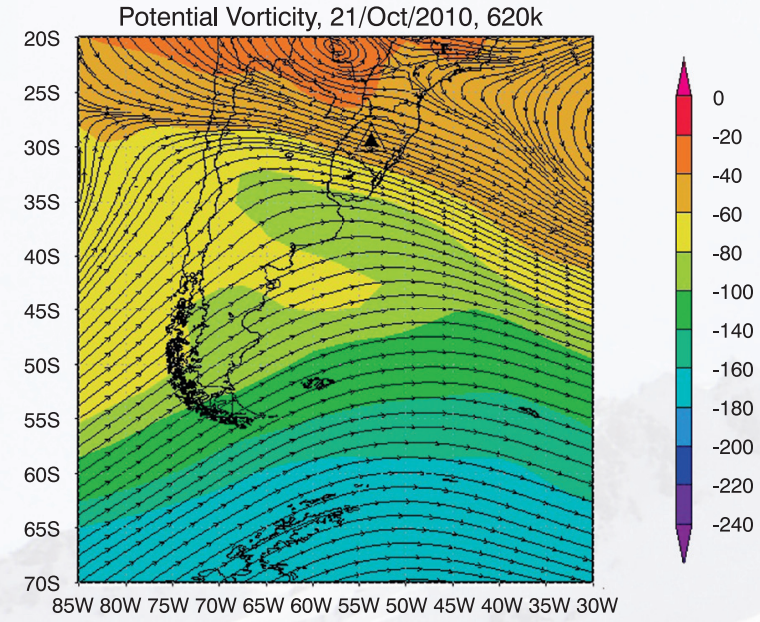

GraDS: COLA/IGES
2011-10-27-13:28
Potential Vorticity, 21/Oct/2010, 620k

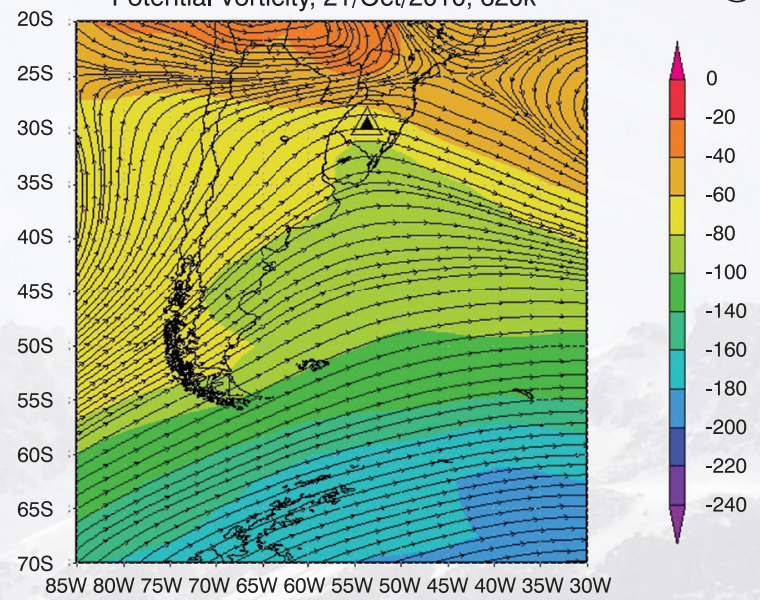

(a)

140

160

$-240$

(b)

2011-10-27-13:28

(c)

OMI Total Ozone Oct 20, 2010
Backward trajectory ending at 0000 UTC 23 Oct 10 CDC1 Meteorological Data

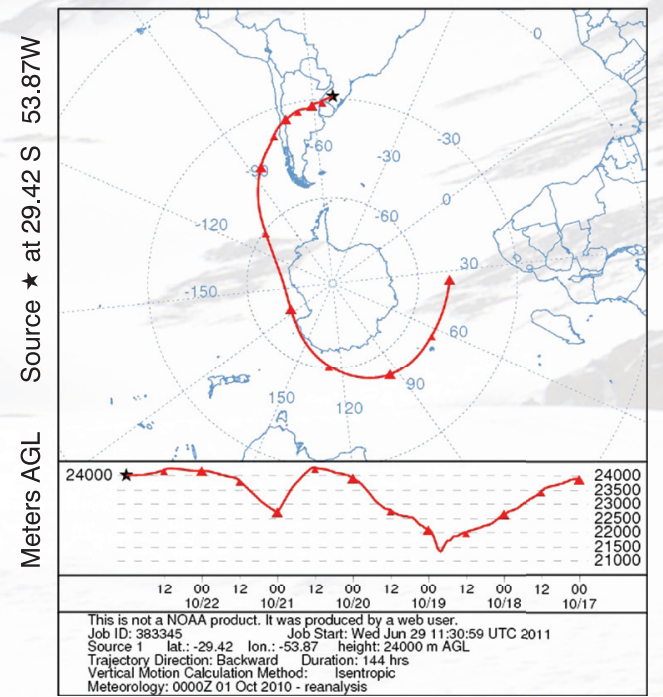

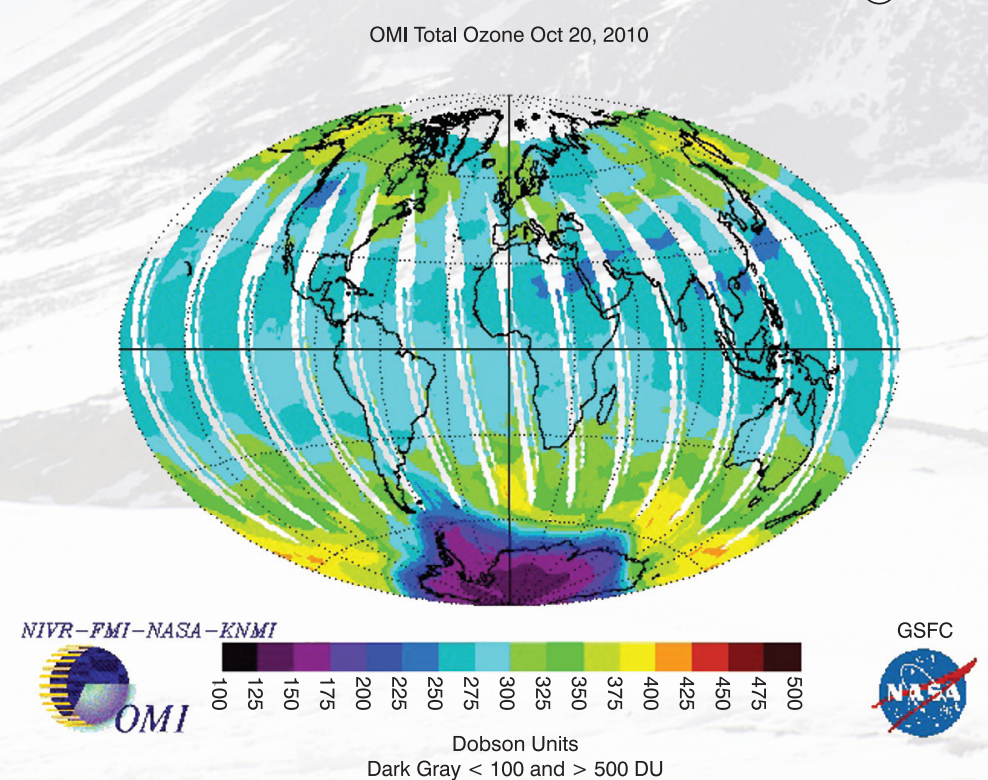

Figure 1. Event of the Antarctic Ozone Hole influence over SSO occurred at October, $22^{\text {th }}, 2010$. a) Maps showing of the increase of the absolute potential vorticity at the level of $620 \mathrm{~K}$ from $21^{\text {th }}$ to $22^{\text {th }}$, b) backward trajectory generated with the HYSPLIT model showing the polar origin of the air mass over SSO and

c) image generated using data from OMl for October, $20^{\text {th }}$ showing a filament of poor ozone air mass reaching South America. 
Potential Vorticity, 21/Oct/2011, 620k

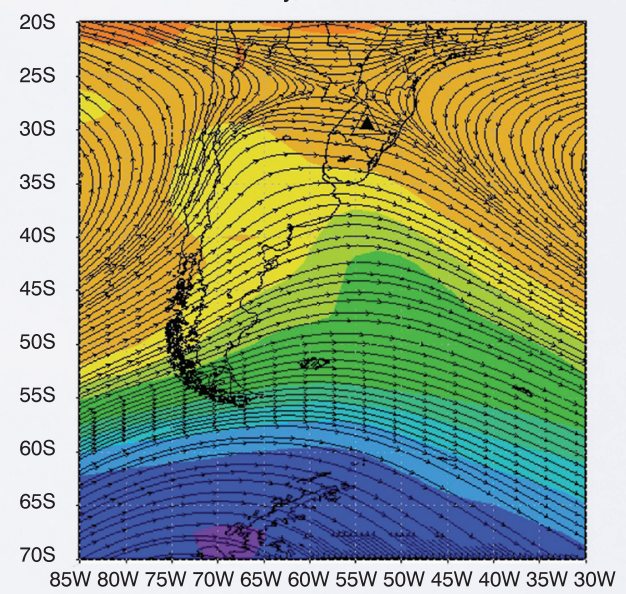

GraDS: COLA/IGES
Potential Vorticity, 21/Oct/2011, 620k

(a)

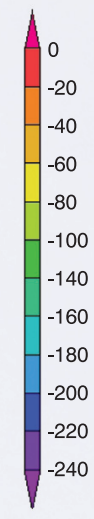

2012-05-02-16:59

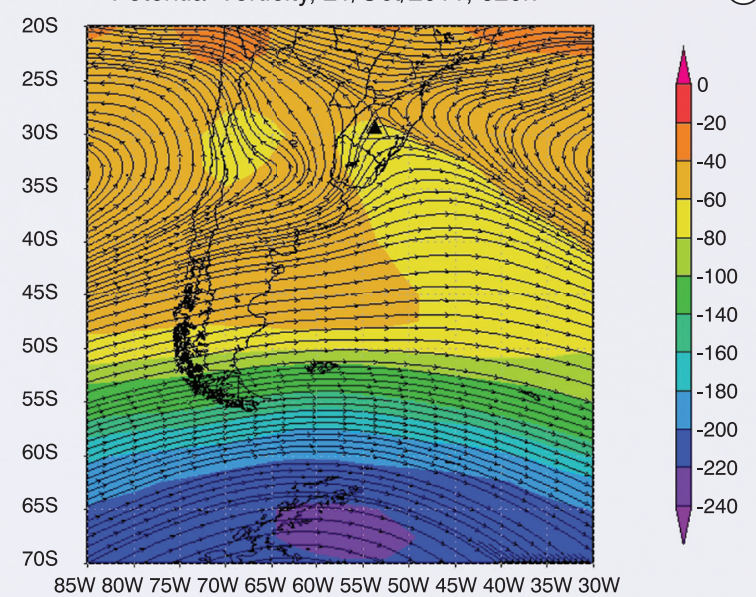

2012-05-02-16:59

(b)

NOAA HYSPLIT MODEL

Backward trajectory ending at 0000 UTC 22 Oct 11 CDC1 Meteorological Data

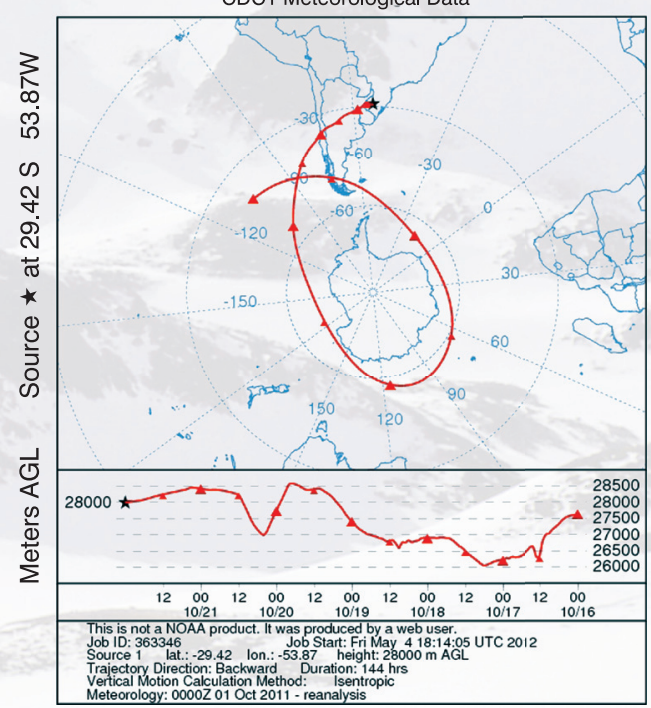

OMI Total Ozone Oct 19, 201

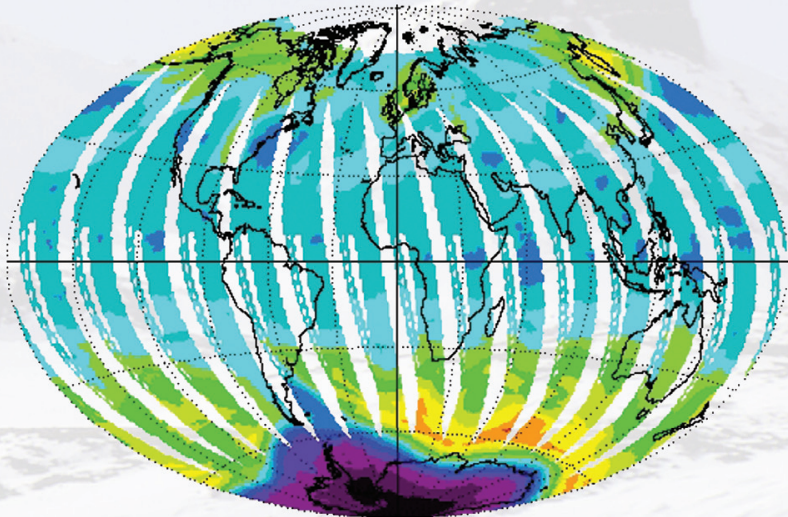

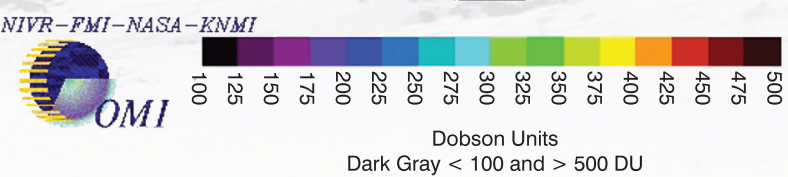

Figure 2. Event of the Antarctic Ozone Hole influence over Southern Space Observatory occurred at October, 21 th, 2011 . a) Maps showing of the increase of the absolute potential vorticity at the level of $620 \mathrm{~K}$ from $20^{\text {th }}$ to $21^{\text {th }}$ of October, $2011, \mathrm{~b}$ ) backward trajectory generated with the HYSPLIT model showing the polar origin of the air mass over Southern Space Observatory and c) image generated using data from OMI for October, $19^{\text {th }}$ showing a filament of poor ozone air mass reaching South America.

in 2010 and 3 events in 2011, with average ozone decreased about $6.3 \pm 2.1 \%$ when compared with climatological means.

\section{Acknowledgements}

This work integrates the National Institute of Science and Technology Antarctic Environmental Research (INCT-
APA) that receives scientific and financial support from the National Council for Research and Development (CNPq process: $n^{\circ}$ 574018/2008-5) and Carlos Chagas Research Support Foundation of the State of Rio de Janeiro (FAPERJ nº E-16/170.023/2008). The authors also acknowledge the support of the Brazilian Ministries

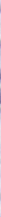


of Science, Technology and Innovation (MCTI), of Environment (MMA) and Inter-Ministry Commission for Sea Resources (CIRM). Acknowledgements also to
PIBIC/UFSM-CNPq/MCTI and CAPES for fellowships, NASA/TOMS and NCEP/NCAR for the data, and NOAA for HYSPLIT model.

\section{References}

Brinksma, E.J.; Meijer, Y.J.; Connor, B.J.; Manney, G.L.; Bergwerff, J.B.; Bodeker, G.E.; Boyd, I.S.; Liley, J.B.; Hogervorst, W.; Hovenier, J.W.; Livesey, N.J. \& Swart, D.P.J. (1998). Analysis of record-low ozone values during the 1997 winter over Lauder, New Zealand. Geophysical Research Letters. 25(15):2785-2788. http://dx.doi.org/10.1029/98GL52218

Danielsen, E.F. (1968). Stratospheric-tropospheric exchange based on radioactivity, ozone and potential vorticity. Journal of Atmospheric Science, 25: 502-18.

Gupta, S.; Lal, S.; Venkataramani, S.; Rajesh, T.A. \& Acharya, Y.B. (2007). Variability in the vertical distribution of ozone over a subtropical site in India during a winter month, Journal Atmospheric Terrestrial Physics, 69: 1502-1512. http://dx.doi. org/10.1016/j.jastp.2007.05.011

Hoskins, B.J.; Mcintyre, M.E. \& Robertson, A.W. (1985). On the use and significance of isentropic potential vorticity maps, Quarterly Journal of the Royal Meteorological Society, 111: 877-946.

Jing, P.; Cunnold, D.M.; Yang, E.S. \& Wang, H.J. (2005). Influence of isentropic transport on seasonal ozone variations in the lower stratosphere and subtropical upper troposphere. Journal of Geophysical Research, 110(D10110). http://dx.doi. org/10.1029/2004JD005416

Kirchhoff, V.W.J.H.; Schuch, N.J.; Pinheiro, D.K. \& Harris, J.M. (1996). Evidence for an ozone hole perturbation at $30^{\circ}$ south. Atmospheric Environment, 33(9):1481-8.

Marchand, M.; Bekki, S.; Pazmino, A.; Lefèvre, F.; Godin-Beekmann, S. \& Hauchecorne, A. (2005). Model simulations of the impact of the 2002 Antarctic ozone hole on midlatitudes. Journal Atmospheric Science, 62: 871-884.

Narayana Rao, T.; Kirkwood, S.; Arvelius, J.; von der Gathen, P. \& Kivi, R. (2003). Climatology of UTLS ozone and the ratio of ozone and potential vorticity over northern Europe. Journal of Geophysical Research, 108(D22): 4703. http://dx.doi. org/10.1029/2003JD003860

Perez, A.; Crino, E.; de Carcer, I.A. \& Jaque, F. (2000). Low-ozone events and three-dimensional transport at midlatitudes of South America during springs of 1996 and 1997. Journal of Geophysical Research-Atmospheres. 105(D4): 4553-4561. http://dx.doi.org/10.1029/1999JD901040

Pinheiro, D.K.; Leme, N.P.; Peres, L.V. and Kall, E. (2011). Influence of the Antarctic ozone hole over South of Brazil in 2008 and 2009. National Institute of Science and Technology Antarctic Environmental Research. 33-37.

Prather, M. \& Jaffe, H. (1990). Global impact of the Antarctic ozone hole: chemical propagation. Journal of Geophysical Research, 95: 3413-92.

Semane, N.; Bencherif, H.; Morel, B.; Hauchecorne, A. \& Diab, R.D. (2006). An unusual stratospheric ozone decrease in Southern Hemisphere subtropics linked to isentropic air-mass transport as observed over Irene $\left(25.5^{\circ} \mathrm{S}, 28.1^{\circ} \mathrm{E}\right)$ in midMay 2002. Atmospheric Chemistry and Physics, 6: 1927-36. 